\title{
Beyond walking and cycling: scoping small-wheel modes
}

Stephen W. Lorimer BA, MPhil, PhD, MRTPI

Research Associate, Imperial College Business School, Imperial College London, London, UK
Stephen Marshall PhD, DipUD, MCIT, MIHT

Reader, Bartlett School of Planning,

University College London, London, UK

Active travel beyond walking and cycling - by small-wheel modes such as inline skating, skateboarding and push scooting, among others - needs more understanding in terms of the design, maintenance and management issues it may present in the future. These modes - especially their use for travel rather than leisure pursuits - are rarely quantified outside of accident statistics and the focus of qualitative study in the governance of public space conflict or the sociology of childhood activities. This paper reports on a scoping study exploring the potential for small-wheel modes among other means of 'human locomotion'. The study first recruited local transport officers and people using these modes, as well as academic experts. The study found that there are differences between the views of planning officers and users of these modes that need to be investigated further to arrive at solid conclusions and advice for the design, maintenance and management issues needed both now and in a future that allows more variety and choice in human locomotion for active travel. The use of user-generated digital data for data capture, analysis and mapping was also explored.

\section{Introduction}

Policies for sustainable cities have traditionally promoted active travel for reasons of health and equity as well as resource use and improving the efficiency of infrastructure. This work puts its focus on self-sufficiency in transport from locomotion that only depends on a person's needs, capabilities and inclinations for any journey undertaken. Cities with more active human locomotion, or humanpowered transport, have the potential to offer choices to people ranging from those with time constraints who can move quickly with sufficient effort, to those who wish to take their time in a comfortable fashion.

However, active travel does not just mean walking and cycling, but can include travel by small-wheel modes: inline skates, skateboards and push scooters. These modes could form a more positive part of a wider agenda - that of 'Cities for Human Locomotion' (Marshall and Lorimer, 2013). This invites questions about what such a city might look like - a futuristic city with 'rollerblade arcades' and 'skating skyways' or a restored traditional city based on short blocks and multifunctional streets, adapted for the twenty-first century?

These issues need exploring because transport and urban planners still do not know enough about the problems, solutions, costs and benefits of a city that optimises human locomotion. Scholars have for years been concerned about 'making cycling irresistible' (Pucher and Buehler, 2008) and promoting a walking city as a just, equitable city (Burton, 2000). Recent research has highlighted the importance of active lifestyles on health - and therefore the potential contribution of activity not only to mobility, but the nation's health, longevity and wider wellbeing (Ekelund et al., 2015; Marshall et al., 2015). If planners and engineers move beyond walking and cycling to plan and promote more diverse forms of human locomotion, a more agile city may begin to emerge. The effect of these actions could be felt on important urban issues such as air and noise pollution, economic competitiveness and inclusivity. However, as yet there is a lack of knowledge about small-wheel modes. In effect, there is a vicious circle whereby 'the lack of knowledge about the full potential for human-powered modes leads to a lack of provision; this discourages use of these modes; and their invisibility hinders the political will to cater for their use' (Marshall and Lorimer, 2013: p. 516).

This paper focuses on the potential for use, design and regulation of urban streets for inline skates, skateboards and scooters, which are referred to collectively as (human-propelled) small-wheel modes, which have wheels typically less than $5 \mathrm{~cm}$ in diameter. (This therefore excludes motor-propelled equivalents of these, and also human-propelled modes with larger wheels such as unicycles, bicycles, tricycles, wheelchairs) Users, regulators and experts in the field all gave their views on the streetscape of cities, collected from interviews in person alongside exploratory research using data captured by way of digital technologies. The findings highlight the similarities and differences in the issues and concerns raised by different groups. In addition, new observational data collection methods can test how well user needs are assessed and met. This paper aims to provide a small step forward to help open up the research agenda for small-wheel modes.

\section{Literature review}

The relevant literature on street design for human locomotion outside of walking and cycling - in particular, for small-wheel modes - has evolved from the perspective of conflict and negotiation of space. This conflict manifests itself in a preponderance of studies 
of injury risk, regulation and law, and user behaviour. Injuries from skateboarding and rollerblading are the most recurrent themes in the literature, with conflict over access to road space and public space the second most written-about topic. There has been comparatively less attention paid in research and practice to how these modes can be promoted with sensitive design and retrofitting of urban streets.

\subsection{Injury risk}

The majority of literature on small-wheel modes focuses on injury risk. There is a high level of relevant research funding available in medicine and epidemiology, and statistics on hospital attendance for related broken bones are readily available. The prevalence of injuries has often been dubbed 'new' as far back as the 1960s and 1970s (Allum, 1978; Schuman, 1967). The language of studies into street design frequently mentions the dangers of mixing these nonmotorised, but faster, forms of personal transport with pedestrians (Konkin et al., 2006; Powell, 2003; Zalavras et al., 2005). The literature also examines the public health implications of allowing children and teenagers to use public spaces and streets using nonstandard human locomotion. Some epidemiologists have started to apply spatial analysis to the study of the injuries associated with these forms of locomotion in cities (Keilani et al., 2010; Lironi et al., 2001; Schuman, 1967).

Some recurring themes were drawn from the literature. First, research into the use of these modes as a way of commuting or transport is understudied. This can be partly attributed to the ease of recruiting in parks and shops instead of on streets in studies of the frequency and location of injuries. Second, studies repeated the connection between the most experienced skateboarders and increased injury rates. The reasons for this is the likelihood of the most experienced skaters to attempt tricks of increasing difficulty, while differences between people with lesser levels of experience were not significant. Third, it should be noted that the users are overwhelmingly male and urban (Borden, 2001; Karsten and Pel, 2000; Page et al., 2012). Clearly, this has implications for equity or distributional consequences for policy attention and investment.

These conclusions prompt further study around the connection between the use of these non-traditional modes for transport, as the presentation of injuries may be more connected with attempting tricks than collisions and falls connected with more straightforward movements on streets and pavements that are the focus of the present study.

\subsection{Governance and the law}

There is a long history of consternation in the regulation of public space about non-traditional forms of human locomotion (Borden, 2001; Stratford, 2002; Stratford and Harwood, 2001; Vivoni, 2009). This nervousness comes from the need to be accommodating towards people who need alternative methods to get around because they are not able to walk - traditionally this would have been just in wheelchairs, but people may also be using other methods. Children use scooters to 'keep up' with adults (Haze, 2001). People practice with their skateboards and rollerblades in public spaces as a place to see and be seen (Keilani et al., 2010; Stratford, 2002; Vivoni, 2009).

The regulation of these types of activities has been debated among those in active travel as to whether these modes deserve support and attention in the same way that walking and cycling do. Stratford and Harwood (2001) describe this as the conflict between 'feral' and 'normal' travel. There is also a 'problem' of skating that has been investigated indistinguishably from the 'problem' of young people using public space at hours that are deemed antisocial (Stratford, 2002). Borden (2001) proposes that originally these modes operated in 'found space' that was appropriated and colonised, followed by skateboarding becoming part of capitalism and architecture as commodity, resulting in new sociospatial conflicts and censorship in urban space. On rollerblades, there has been documented confusion over where they should go on the street (carriageway or footpath). Some guidelines have been produced in the USA that encourage authorities both to consider skating as something that takes place on the carriageway but also to recognise skaters as vulnerable road users (Osberg et al., 2000).

Some recurring themes were drawn from the literature. Regulations are haphazard and confusing to all road users, as they may change according to by-laws from one local authority to another and from one space to another. This can easily lead to conflict between these non-traditional and 'normal' users. This points to the need to consider these distinct modes in their own right, and not just as modes close enough to either walking or cycling to classify them in those existing categories. It also prompts questions on whether the modes are being legislated against because of their nature or by the (assumed) nature of the users or their occupation of public space.

\subsection{Allowing children and teenagers to play}

There is another strand of literature related to injury and governance of streets dedicated to the specific role that these modes have in the development and wellbeing of children and adolescents. Young people predominate in the use of alternative and non-traditional modes of transport. As mentioned above, there are concerns over antisocial behaviour in public space (Jenson et al., 2012), but others have anxieties that these fears are preventing active play and active travel among children and young people (Vivoni, 2013; Woolley et al., 2011).

Active travel among children is often researched from the perspectives of traffic safety from school to home (Committee on Injury, Violence, and Poison Prevention and Council on School Health, 2007; Mackett et al., 2007). There is also research into the impact of the use of these modes of transportation on social interaction and play among young people (Khan, 2009; Taylor and Khan, 2011; Woolley and Johns, 2001).

From this, it is possible to conclude that these modes can be a new and innovative way of encouraging active travel among the young. This process is already underway in scooter use among children, and is likely to continue with skateboarding and inline skating as 
the new generation of children with scooters 'graduate' to speedier and more motor-skill-demanding modes. That said, concern over traffic safety around schools and the school run tends to dissuade active encouragement of these modes in favour of walking. The reaction to this may be simply to return to being driven to school or around the city due to distance and time constraints.

\subsection{Street design}

Street and public space design has considered small-wheel modes as part of a 'leisure landscape' (Stevens and Dovey, 2004). Previous work on design has ranged from occupational therapy (Mulholland et al., 2009), crowd-sourcing (Hara et al., 2013), play spaces and parks (Vivoni, 2009) to 'play streets' (Jenson et al., 2012; Khan, 2009; Woolley and Johns, 2001). Evidence gathering generally is also scant; official transport statistics collected by governments will typically group these modes with 'walking' (Department for Transport, 2014), preventing evidence-based design and policy.

Considerations of street design have centred around how councils and town centre managers use design to prevent tricks and directing users away from pedestrian users of streets and spaces. This practice leads to a 'state of flux of skate spaces' (Woolley and Johns, 2001) where users appear and disappear from streets and spaces depending on the addition or removal of treatments. When retrofits to public space occur, such as with new lugs, this increases interest in the space as a challenge. New treatments also attract due to their status as 'unknown terrains' (Borden, 2001).

\subsection{Implications}

Overall, there seems to be a need for more research into the modes themselves, their use, their users, and how to provide for them. There is work to be done on the issues around designing cities that accommodate these forms of human locomotion. There has been a focus in the past on street design for specific activities using these forms of human locomotion in streets and spaces. This research seeks to build on this work by identifying the issues associated with streets and spaces designed to accommodate almost any form of transport. There are important questions associated with spaces for children and teenagers to play and their injury risk, but that is not the focus of this investigation. The present study approaches these forms of human locomotion as transport modes - for example, getting from 'A' to 'B'. The focus is on small-wheel modes - inline skates ('rollerblades'), skateboards and scooters.

\section{Methods}

The present study aimed to gain alternative perspectives on the use of and provision for small-wheel modes. Ideas were elicited in two different ways. Most of this paper will concentrate on focus groups using an interview protocol. In addition, self-generated data were analysed from people using these modes through streets and spaces.

\subsection{Focus groups and interviews}

Two focus groups and a panel of interviews were set up with a mix of participants to explore a broad range of perspectives on nonstandard forms of human locomotion. Purposive sampling was used to attempt to obtain a balanced sample of transport planning practitioners, street users and transport experts.

The focus groups were set up in London in June 2013. Each group met for between 1 and $2 \mathrm{~h}$ and each consisted of nine people. Users were recruited by way of visits to the Serpentine Road in Hyde Park, London, and a common gathering point for inline skaters and skateboarders to practise and the starting point for organised group skates through central London. Group leaders of this skate were contacted and were part of the recruiting process. Experts were invited by the Bartlett School of Planning, University College London, to be part of a symposium on the merits of promoting these forms of human locomotion. The focus groups were convened in a field setting for users and professionals and in a seminar setting for experts, facilitated by the research team. Field participants completed a release form to allow their data to be used in this study.

An interview panel was set up to elicit the view of transport professionals. These professionals were recruited first through the interest group Movement for a Liveable London, a gathering of engineering, design, transport planning and public health professionals that wish to promote walking and cycling in the city region. A second wave was recruited from current and former staff responsible for streets at Transport for London and the 'miniHolland' cycling infrastructure project at the Royal Borough of Kingston upon Thames.

These three groups - users, practitioners and academics - allowed for a wide range of views and attitudes around using these forms of human locomotion as transport. Seven of the participants (28\%) were transport professionals who composed and recommended local changes to transport planning policy and implementation plans. Nine $(36 \%)$ of the participants were inline skaters who were street users, and nine $(36 \%)$ were experts in a variety of areas including transport planning, engineering, urban planning, geography, archaeology and architecture.

The research team developed an initial topic guide for each group from the literature review. Later topic guides were derived from each group's responses. A summary of previous groups' discussions were presented to each group. The views and attitudes of the first wave of interviews with transport professionals helped developed topics for discussion at the following focus groups (Table 1; Figure 1).

\subsection{Data capture, analysis and mapping}

In the absence of formal statistics or a detailed observational survey, the authors were able to learn about actual use of smallwheel modes through data obtained from smartphones that are increasingly being used by citizens in the city. One example of this kind of technology is tracking software that takes advantage of the accelerometer, global positioning systems, wifi router locations and mobile mast triangulation in smartphones. However, commuter-focused software (e.g. CO2TOGO, CarbonDiem) 


\begin{tabular}{|c|c|}
\hline Starting topics & Emerging topics \\
\hline $\begin{array}{l}\text { - Understanding the impact } \\
\text { of paving and road surfacing } \\
\text { - The importance of street } \\
\text { design }\end{array}$ & $\begin{array}{l}\text { - Kerb and carriageway } \\
\text { interaction } \\
\text { - } \quad \text { Role of bicycle paths, } \\
\text { footway and carriageway } \\
\text { for transport } \\
\text { - Skill and participation } \\
\text { level } \\
\text { - Legal standing of these } \\
\text { modes }\end{array}$ \\
\hline
\end{tabular}

Table 1. Starting and emerging topics

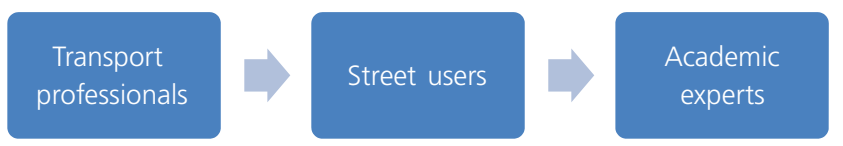

Figure 1. Path of emerging topics in the human locomotion focus

is limited to collecting data on walking and cycling routes. Exercise-focused software does collect data about routes where users are skating, skateboarding or scooting. Although the routes taken have a leisure orientation and the focus of this paper is on 'everyday' commuting and shopping, this form of data collection can point towards future studies.

The research team used data from Strava, an online community where people share their exercise routes and times, to examine if posted data supported stated claims that topography negatively affected the performance of small-wheel modes. One hundred and sixty-three traces posted from in and around London were used. The users were not individually recruited, as a licence to use their data for non-commercial purposes was purchased from Strava, and permission for re-use of all data, unless the user makes their data private, is given by all users as part of Strava's terms and conditions (Strava, 2014). Each of the traces had a distance, time and elevation gain attached to them, and the average gradient was calculated (of uphill segments only) and the average speed. As the data contained elevation gain only, zero gradient could contain negative numbers. Example journeys were compared to estimated travel times for that time and data using the Transport for London journey planner (Transport for London, 2015). Finally, a map was generated from the journey traces to indicate the potential for mapping small-wheel modes from usergenerated data.

\section{Findings}

\subsection{Interview panel and focus groups}

This section summarises the themes that emerged from each of the groups (Table 2) who were invited to discuss and explore issues affecting the small-wheel modes and their provision. The participants described and qualified these issues.

\subsubsection{Interview panel group: transport professionals (wave 1: P1-P2, wave 2: P21-P25)}

Paving and road surfacing were identified as the most important issues by the respondents. The need for smooth surfaces was identified as an issue for users, especially the use of concrete as a surface instead of asphalt (P1, P2, P21, P23). Street furniture could increase conflict with pedestrians on pavements, which could be ameliorated by increasing pavement widths (P23, P25). Bike tracks and paths were seen as a positive attribute of street design (P2) but current best practice on track width risks conflict with cyclists (P21, P24, P25). Speed bumps were seen as a positive attribute of street design (P1), but smooth, dropped kerbs and raised tables were optimal for allowing safe crossing at junctions (P2, P22, P23, P24).

\subsubsection{Focus group 1: street users (P3-P11)}

Like the professionals, the respondents identified paving and road surfacing as the most important issues. Road surfacing is much

\begin{tabular}{llccc}
\hline Topic & Topic introduced by & 1. Professionals & 2. Users & 3. Experts \\
\hline Paving/road surfacing & Author & ++ & ++ & ++ \\
Street design & Author & 0 & 0 & ++ \\
Kerb/carriageway interaction & Transport professionals & + & 0 & 0 \\
Role of bicycle paths for & Transport professionals & + & + & 0 \\
skateboarding/rollerblading & & & + & 0 \\
Skill building & Street users & & + & + \\
Ambiguous legal situation & Street users & & + & + \\
Promotion & Street users & & + \\
\hline
\end{tabular}

0 , neutral to the topic as an issue; +, somewhat important issue; ++, very important issue 
more of an issue for them than it would be for cyclists (P3). 'Heavy' or bumpy paving on the carriageway is much more likely to aggravate them (P3) and create a different route choice than street design would, within limits, as going down a dual carriageway such as Park Lane was not desirable (P4). Conflicts between cycling and rollerblading street management can occur. For instance, when gravel is put on cycle paths to slow cyclists down in Hyde Park (not to harass pedestrians), it makes the path unusable and forces rollerbladers out into the middle of the road, affecting their safety and comfort using the road (P4).

The incidence of skills that people had developed was highlighted as a minor issue. People comfortable using the streets on a weekday are significantly different from those who are comfortable just on the weekend as they have quite different route choices (P5). People who practice stunts and tricks are more likely to be more comfortable using the streets (P6).

The incidence of places where rollerblades could legally use the street was highlighted as a minor issue. Police seem to be unaware of the legal situation of rollerblading on carriageways and footpaths and tend to enforce their personal preferences instead (e.g. one corner put on the carriageway, next corner put on the pavement) (P7). Skaters felt like a marginal group on the roads and are treated as such by motor vehicle users, perhaps in the same way cyclists felt 10 years ago $(\mathrm{P} 7)$.

The promotion of these modes as valid forms of transport was highlighted as a minor issue. Promotion is far behind other European cities as group skates are more than ten times larger in Paris, Berlin, etc. (P8).

\subsubsection{Focus group 2: academic experts (P12-P20)}

Like the professionals and users, paving and road surfacing were identified as very important issues by the respondents. The best surfaces are wide, shared, cleaned and drained (P12). While the research team alluded to the possibility of roofing over streets to create an artificially dry environment, one respondent countered that one of the attractions of these modes was getting out in the fresh air (P14). Skateboarding, for example, is faster than walking on flat pavements but the user can quickly get off the board if it becomes slower than walking on uphill inclines.

Street design was identified as a very important issue by the expert group. There seems to be a culture that is suspicious of shared space while other countries, notably Germany, are generally happy with shared space, even at the planning stages (P13). The busiest streets will always be the most attractive to all street users, including those on non-traditional modes (P12). If one chooses to facilitate these modes, pushing them onto 'quietways' is unlikely to be successful (P12). Separation of spaces, on the other hand, will decrease the male, fast bias in these modes (P15).

The ambiguous legal situation was highlighted as a minor issue. Examples of legal demonisation are by-laws in the City of London for using a skateboard and in parts of Derby for even carrying a skateboard (P12).

The promotion of these modes as valid forms of transport was highlighted as a minor issue. Many of these modes are associated with children - for example, microscooters (P14). There is a community spirit but there is a lack of coherent organisation and definite anarchic tendencies (P12).

\subsection{Data capture, analysis and mapping}

This section provides an initial impression of the kind of data available that help to indicate the potential range of use and competitiveness of small-wheel modes.

\subsubsection{Testing user needs: street gradients and speeds using digital traces}

Uphill segments were cited as an important brake on speed and therefore the usability of small-wheel modes. Using overall time, distance and elevation change data from Strava, no confirmed effect was found on speed in rollerbladers $(N=96)$ and skateboarders ( $N=14$ ), but a stronger, but not confirmed, effect on speed on scooter users $(N=53)$ was found. A correlation between gradient and speed could not be proved, but these data point towards the potential of digital data on movements around the city to test stated user needs (Figure 2; Table 3).

Some sample journeys were looked into in more detail. These analyses feature four trips for each of the three small-wheel modes, reporting journey location, length and time (Figure 3; Table 4). In this small sample, inline skates were on average fastest, then skateboards and then scooters the slowest. Inline skates were on average going the longest distance, then skateboards, with scooters going the shortest distance. Interestingly, one skate route takes in the Embankment, the Mall and Hyde Park, and beats all other modes. Another skating route takes in Richmond Park and crosses the Thames on a pedestrian footbridge - suggesting good use of off-road routes. Several of these are labelled 'commute' and one is explicitly substituting for the tube (London Underground) during a tube strike.

All the journeys were compared to Transport for London estimates of journey times from the same origin and destination for travelling by underground or rail, bus, bicycle ('moderate' speed) and foot.

- All the small-wheel modes were faster than taking the bus and walking for all journeys but one (the exception, a slow skateboard trip using a slightly circuitous route).

- Even the slowest of the small-wheel modes - the scooter was faster than all bus journeys (and even one tube journey) over the short distances for which it is used.

- Cycling was faster than all scooter trips and most skateboard trips. Cycling was faster than tube and bus for all trips but one (see below).

- Inline skates were faster for all journeys except one inner London trip (when cycle was faster) and a long distance trip (train). In the latter case, inline skating was not surprisingly 


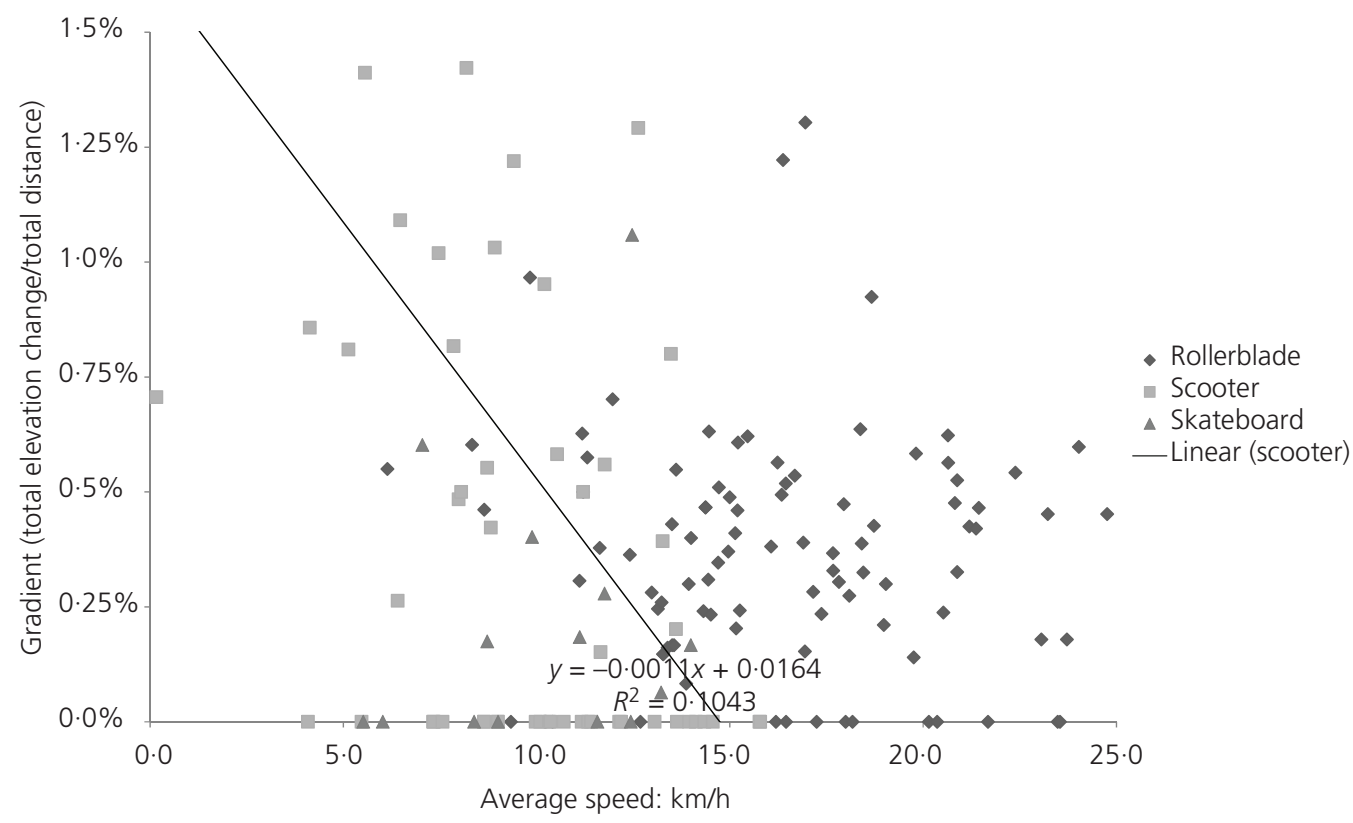

Figure 2. Effect of topography on small-wheel speeds

\begin{tabular}{lccc}
\hline Type & $N$ & Coefficient & $R^{2}$ \\
\hline Scooter & 53 & -1.1 & 0.104 \\
Inline skaters (rollerbladers) & 96 & -0.009 & 0.003 \\
Skateboarders & 14 & 0.02 & 0.031
\end{tabular}

thresholds where different human-powered modes are competitive over different distances.

\subsection{Mapping skating routes}

Finally, survey data for inline skating journeys were collated and mapped, by a member of the extended research team (anonymised acknowledgement). Figure 4 shows skating routes that were publicly available on Strava.com in June 2013. The data source is one that attracts leisure routes as well as commuting routes - for example, the apparent traces in the north-east, of circuits in a park and round a soccer stadium - but this kind of 'crowd-sourced' map

slower than a $23 \mathrm{~km}$ train journey, but actually was faster than the 'moderate' cycling estimate. It is suspected that an inline skater doing a $23 \mathrm{~km}$ journey would be a 'keen athlete', faster than an estimate time for an average cyclist.

- The fastest skateboarder - over a medium-long distance - beat all other modes for that trip. The slowest skateboarder - over a short distance - still beat bus and walking journey times.

- For the shortest trips, and in outer suburbs with distantly spaced stops, public transport may not be competitive, or may simply not be viable (i.e. it was not possible to make the trip by that mode).

In Figure 3 and Table 4, the potential relative competitiveness of small-wheel modes is evident. At a glance, small-wheel modes are much closer to the profile for cycling than for walking. Yet, the lack of a need for cycle parking could be an asset for shorter journeys, and the ability to transfer seamlessly to public transport could be an asset for longer journeys. Note that for the shortest journeys, it is not evident that the Transport for London algorithm takes time for cycle parking into account. This is suggestive for further research. Overall, this chart suggests possibilities for further research finding

\section{Conclusions}

Many transport planning professionals, road users and academic experts welcome discussion about the usefulness of non-standard modes of human locomotion as transport. Modes such as inline skating, skateboarding and scooting were evaluated as valid forms of getting around the city for work, school and leisure instead of being used just for the skating/blading etc. activity itself. Issues associated with designing for a city that can offer the choice of these modes for getting around centred on paving and road surfacing as the most important issue, followed by others such as street design, the legal situation and promotion. However, the small self-selected sample in this study limits the ability to make wider assumptions about the urban design of a city that can make these accommodations.

All of the participants bemoaned the lack of quality surfaces around London that would be welcoming for these modes. First, the smaller the wheel, the more sensitive the mode is to surface, and all of these modes have smaller wheels than bicycles. Second, the ambiguous 


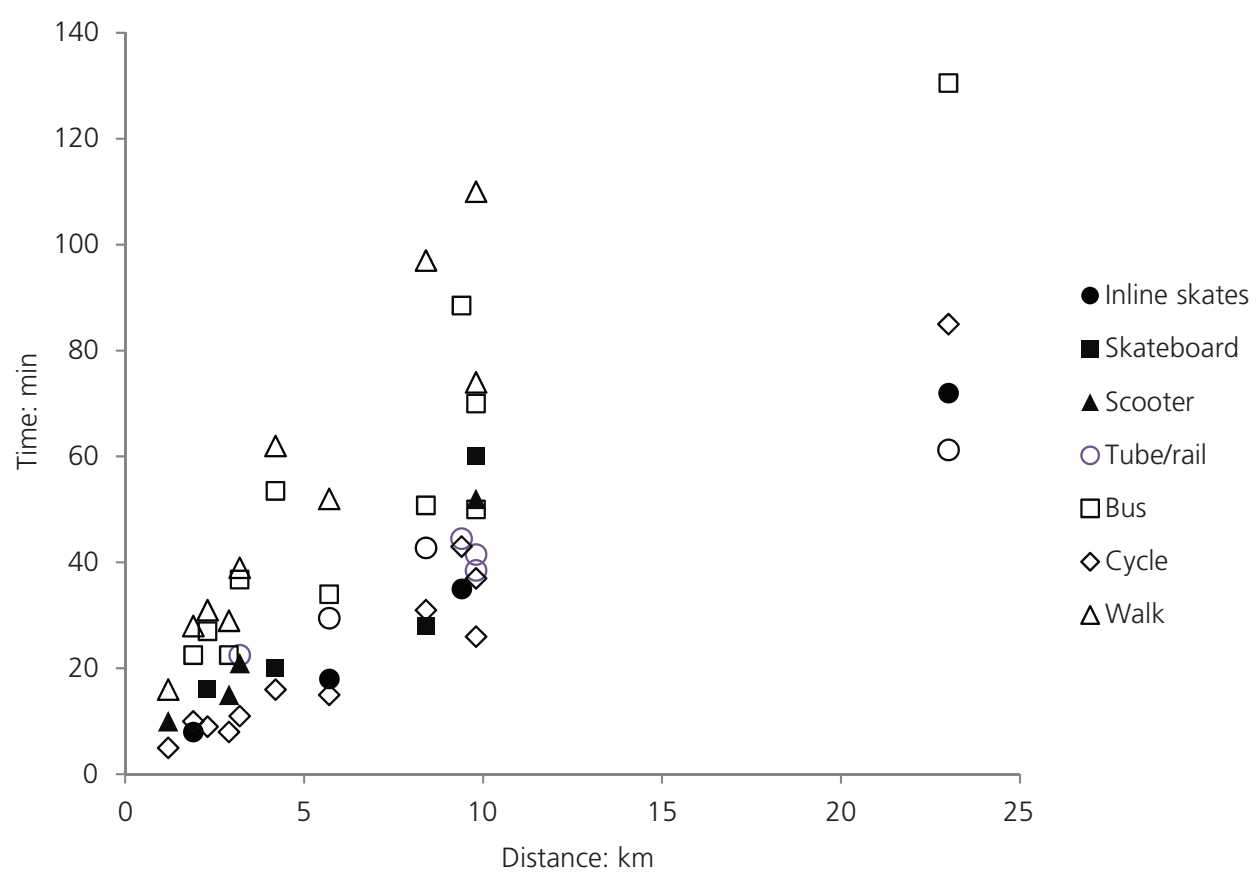

Figure 3. Small-wheel journey times against estimated journey times for rail, bus, bicycle and foot

legality of using these modes on footpaths and carriageways does not help transport planners provide for these modes. However, the user group was limited to inline skaters, so more work is needed to validate these concerns with other modes. None of the participants voiced any significant objections to the idea of these modes being valid ones for urban dwellers to get around their city. There was a smaller than expected amount of discussion about the cultural differences of the many groups and subgroups that are found in a city. However, contrary views came from transport professionals working on the ground in London. The focus instead was on the lack of promotion of these modes generally, which should be explored further in a larger study into the desirability of designing for them.

The use of digital data enabled insights to be gained into the speed of small-wheel modes and the relation to gradient, and to compare sample journeys against alternative modes. Here, small-wheel modes can be surprisingly time-efficient to those who wish to get themselves around by their own power but not by walking or cycling. Exploratory research was done using digital traces across London that users of these small-wheel modes posted using tracking software. The position was tested that users needed flat roads to maximise the potential of small-wheel modes but could not prove it. Further data collection might show a strong connection, especially for scooter use. In addition, travel speeds for journeys using these modes are surprisingly high and can regularly outperform buses in inner city areas as well as walking but they do not outperform cycling.

The mapping and trip analyses give the impression that smallwheel modes are indeed potentially viable, for a range of inner urban trips and even longer suburban or intersuburb trips. The question becomes what are the issues that need to be dealt with when considering policy and provision for these modes.

These methods clearly raise new questions for consideration about how researchers investigate user needs. Are there streets at the same level of the road hierarchy that have different usage patterns due to stated factors such as road surfacing? Does a busy street lead directly to the user's destination? In which places are these forms of human locomotion promoted by users and/or street managers and what is their effect? To what extent are user-generated data representative of routine travel, rather than one-off time trials? What effect will smooth surfaces benefiting these modes have on vehicles and pedestrians? With the wrong materials, people could slip and cars could skid. These questions are important and are related to issues probably raised elsewhere in this special issue around walking and cycling. Heavily trafficked high streets and arterial routes can be both an unpleasant streetscene but desirable as a direct route to many services. The study also suggests more research and debate are needed on the relative benefits of smallwheel modes in terms of the potential benefits to health and wellbeing, including mental health, children's self-reliance and longevity, to be considered against the accident disbenefits of these modes.

The results of this study are currently being reviewed for use both to inform future planning policy and to design trials of future street design interventions. It also points to the possible consideration of a wider array of future 'alternative' modes of human-powered 


\begin{tabular}{|c|c|c|c|c|c|c|c|}
\hline Journey & $\begin{array}{l}\text { Speed: } \\
\mathrm{km} / \mathrm{h}\end{array}$ & $\begin{array}{l}\text { Distance: } \\
\quad \mathrm{km}\end{array}$ & $\begin{array}{l}\text { Journey } \\
\text { time: } \min \end{array}$ & $\begin{array}{l}\text { Underground } \\
\text { (*or rail) }\end{array}$ & $\begin{array}{c}\text { Cycling } \\
\text { ('moderate') }\end{array}$ & Bus & $\begin{array}{l}\text { Walking } \\
\text { ('average }\end{array}$ \\
\hline \multicolumn{8}{|l|}{ Scooter } \\
\hline $\begin{array}{l}\text { Local trip within south- } \\
\text { western inner suburb }\end{array}$ & 7 & $1 \cdot 2$ & 10 & - & 200 & - & 63 \\
\hline $\begin{array}{l}\text { Local trip within south- } \\
\text { western outer suburb }\end{array}$ & 12 & $2 \cdot 9$ & 15 & - & 188 & 67 & 52 \\
\hline $\begin{array}{l}\text { Central London (commute } \\
\text { from terminal station to city) }\end{array}$ & 9 & $3 \cdot 2$ & 21 & 96 & 195 & 59 & 55 \\
\hline $\begin{array}{l}\text { Inner London (commute } \\
\text { from city to inner suburb) }\end{array}$ & 11 & $9 \cdot 8$ & 52 & 135 & 141 & 74 & 47 \\
\hline $\begin{array}{l}\text { Average } \\
\text { Skates }\end{array}$ & 10 & $4 \cdot 275$ & & & & & \\
\hline $\begin{array}{l}\text { Central London mainly } \\
\text { within Hyde Park }\end{array}$ & 14 & 1.9 & 8 & - & 80 & 36 & 29 \\
\hline Across central London & 19 & $5 \cdot 7$ & 18 & 61 & 120 & 53 & 35 \\
\hline $\begin{array}{l}\text { City to inner western suburb } \\
\text { (by Embankment, Hyde Park) }\end{array}$ & 16 & $9 \cdot 4$ & 35 & 79 & 81 & 40 & 29 \\
\hline $\begin{array}{l}\text { West End to outer south- } \\
\text { western suburb }\end{array}$ & 19 & 23 & 72 & $118^{*}$ & 85 & 55 & 24 \\
\hline $\begin{array}{l}\text { Average } \\
\text { Skateboard }\end{array}$ & 17 & 10 & & & & & \\
\hline Across inner western suburb & 9 & $2 \cdot 3$ & 26 & - & 178 & 59 & 52 \\
\hline $\begin{array}{l}\text { Across outer south-western } \\
\text { suburbs }\end{array}$ & 13 & $4 \cdot 2$ & 20 & - & 125 & 37 & 32 \\
\hline $\begin{array}{l}\text { From south-eastern inner } \\
\text { suburb to city }\end{array}$ & 18 & $8 \cdot 4$ & 28 & 65 & 90 & 55 & 29 \\
\hline $\begin{array}{l}\text { From eastern suburb to } \\
\text { South Bank }\end{array}$ & 10 & $9 \cdot 8$ & 60 & 145 & 231 & 120 & 81 \\
\hline Average & 12 & $6 \cdot 175$ & & & & & \\
\hline
\end{tabular}

Table 4. Comparative journey times by alternative modes

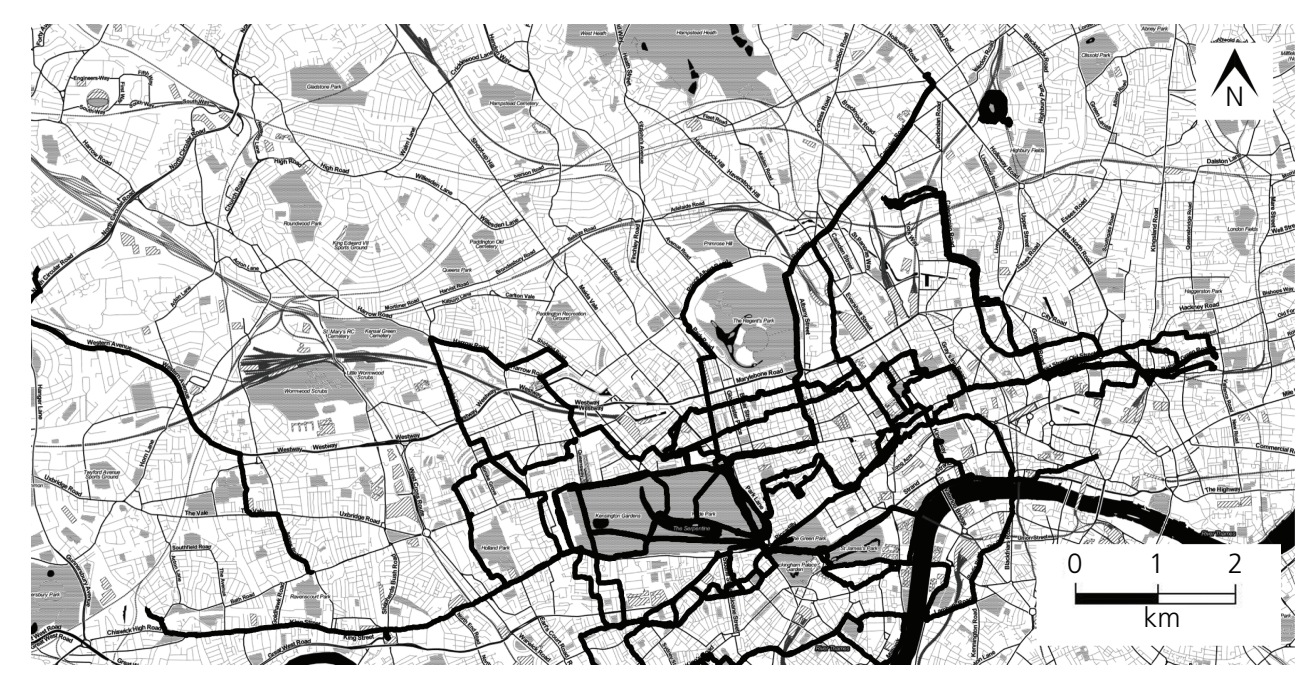

Figure 4. Inline skating routes to and from central London 
transport, including chariot skates (Hornyak, 2009) and bicycle monorails (Singh, 2010), and also motorised equivalents in development such as motorised skateboards (Cohen, 2015), or that are currently in the realm of science fiction, such as hoverboards (Davies, 2013). These alternative futures will all imply an iterative set of processes including vision, development, testing and user participation and policy evaluation, amid which increments of research have a role to play.

\section{Acknowledgements}

The authors would like to thank the UCL grand challenge for sustainable cities small grant fund. They also thank Drs Catherine Holloway and James Cheshire who were co-investigators on the project, and Professors Nick Tyler and Michael Batty for their advice and direction.

\section{REFERENCES}

Allum RL (1978) Skateboard injuries: a new epidemic. Injury 10(2): 152-153.

Borden I (2001) Skateboarding, Space and the City: Architecture and the Body. Berg Publishers, Oxford, UK.

Burton E (2000) The compact city: just or just compact? A preliminary analysis. Urban Studies 37(11): 1969-2006.

Cohen S (2015) This Motorized Skateboard Might Kick Segway to the Curb. OZY. See http://www.ozy.com/good-sht/thismotorized-skateboard-might-kick-segway-to-the-curb/39009 (accessed 13/04/2015).

Committee on Injury, Violence, and Poison Prevention and Council on School Health (2007) School transportation safety. Pediatrics 120(1): 213-220.

Davies S (2013) Delivering on design aspirations [Design Science Fiction]. Engineering Technology 8(8): 52-55.

Department for Transport (2014) National Travel Survey, 2002-2012: User Guidance. See http://doc.ukdataservice. ac.uk/doc/5340/mrdoc/pdf $/ 5340$ _user_guide_2002-2012.pdf (accessed 20/07/2015).

Ekelund U, Ward HA, Norat T et al. (2015) Physical activity and all-cause mortality across levels of overall and abdominal adiposity in European men and women: the European Prospective Investigation into Cancer and Nutrition Study (EPIC). American Journal of Clinical Nutrition 101(3): 613-621.

Hara K, Le V and Froehlich J (2013) Combining crowdsourcing and google street view to identify street-level accessibility problems. Proceedings of the SIGCHI Conference on Human Factors in Computing Systems, CHI '13, ACM, New York, NY, USA, pp. 631-640.

Haze N (2001) Scootermania: implications for pediatric nurses. Pediatric Nursing 27(3): 272-275.

Hornyak T (2009) Strap a Bike to Your Feet with Chariot Skates. CNET. See http://www.cnet.com/news/strap-a-bike-to-yourfeet-with-chariot-skates/ (accessed 20/07/2015).

Jenson A, Swords J and Jeffries M (2012) The accidental youth club: skateboarding in Newcastle-Gateshead. Journal of Urban Design 17(3): 371-388.
Karsten L and Pel E (2000) Skateboarders exploring urban public space: Ollies, obstacles and conflicts. Journal of Housing and the Built Environment 15(4): 327-340.

Keilani M, Krall C, Lipowec L et al. (2010) Skateboarding injuries in Vienna: location, frequency, and severity. $P M \& R$ 2(7): 619-624.

Khan CA (2009) Go play in traffic: skating, gender, and urban context. Qualitative Inquiry 15(6): 1084-1102.

Konkin DE, Garraway N, Hameed SM et al. (2006) Populationbased analysis of severe injuries from nonmotorized wheeled vehicles. American Journal of Surgery 191(5): 615-618.

Lironi A, Battaglin C, Thévenod C and Le Coultre C (2001) Scooter injuries or a chronicle of a new epidemic. Apropos of a prospective study of Geneva cases. Swiss Surgery 7(4): 180-183.

Mackett RL, Paskins J, Gong Y and Kitazawa K (2007) Children's local travel behaviour - how the environment influences, controls and facilitates it. 11th World Conference on Transport Research. See http://trid.trb.org/view.aspx?id=889720 (accessed 02/05/2013).

Marshall S and Lorimer S (2013) Cities for human locomotion. Town and Country Planning 82(12): 514-517.

Marshall S, Milne G, Rook G and Timmerman R (2015) Walking - a step-change towards healthy cities. Town and Country Planning (in press).

Mulholland S, Johnson S, Ladd B and Klassen B (2009) Why urban design matters to occupational therapy. Occupational Therapy Now 11(2). See http://www.caot.ca/otnow/march09/ urbandesign.pdf (accessed 03/05/2013).

Osberg JS, Brubaker RA and Brown M (2000) Developing Public Policies on Skating: General Guidelines and Recommendations. See http://www.metroped.org/skate/ sk_pub_pol.htm (accessed 03/05/2013).

Page JL, Macpherson AK, Middaugh-Bonney T and Tator $\mathrm{CH}$ (2012) Prevalence of helmet use by users of bicycles, push scooters, inline skates and skateboards in Toronto and the surrounding area in the absence of comprehensive legislation: an observational study. Injury Prevention 18(2): 94-97.

Powell EC (2003) Non-motorized vehicles and walkers: going for 'broke'. Clinical Pediatric Emergency Medicine 4(2): 103-111.

Pucher J and Buehler R (2008) Making cycling irresistible: lessons from The Netherlands, Denmark and Germany. Transport Reviews 28(4): 495-528.

Schuman SH (1967) Skateboard injuries in a campus community. Clinical Pediatrics 6(4): 252-254.

Singh T (2010) Google Invests in Shweeb's Pedal-Powered Bike Monorail. Inhabitat. See http://inhabitat.com/googleinvests-in-shweebs-peddle-powered-bike-monorail/ (accessed 20/07/2015).

Stevens Q and Dovey K (2004) Appropriating the spectacle: play and politics in a leisure landscape. Journal of Urban Design 9(3): 351-365.

Stratford E (2002) On the edge: a tale of skaters and urban governance. Social \& Cultural Geography 3(2): 193-206.

Stratford E and Harwood A (2001) Feral travel and the transport field: some observations on the politics of regulating skating in Tasmania. Urban Policy and Research 19(1): 61-76. 
Strava (2014) Terms and Conditions. See https://www.strava.com/ terms\#submitted_content (accessed 13/04/2015).

Taylor MF and Khan U (2011) Skate-park builds, teenaphobia and the adolescent need for hang-out spaces: the social utility and functionality of urban skate parks. Journal of Urban Design 16(4): 489-510.

Transport for London (2015) Plan a Journey. See https://www.tfl. gov.uk/plan-a-journey/ (accessed 15/01/2015).

Vivoni F (2009) Spots of spatial desire: skateparks, skateplazas, and urban politics. Journal of Sport \& Social Issues 33(2): $130-149$.

Vivoni F (2013) Waxing ledges: built environments, alternative sustainability, and the Chicago skateboarding scene. Local Environment 18(3): 340-353.
Woolley H and Johns R (2001) Skateboarding: the city as a playground. Journal of Urban Design 6(2): 211-230.

Woolley H, Hazelwood T and Simkins I (2011) Don't skate here: exclusion of skateboarders from urban civic spaces in three northern cities in England. Journal of Urban Design 16(4): 471-487.

Zalavras C, Nikolopoulou G, Essin D, Manjra N and Zionts LE (2005) Pediatric fractures during skateboarding, roller skating, and scooter riding. American Journal of Sports Medicine 33(4): $568-573$.

\section{WHAT DO YOU THINK?}

To discuss this paper, please submit up to 500 words to the editor at journals@ice.org.uk. Your contribution will be forwarded to the author(s) for a reply and, if considered appropriate by the editorial panel, will be published as a discussion in a future issue of the journal.

Proceedings journals rely entirely on contributions sent in by civil engineering professionals, academics and students. Papers should be 2000-5000 words long (briefing papers should be 1000-2000 words long), with adequate illustrations and references. You can submit your paper online via www.icevirtuallibrary.com/content/journals, where you will also find detailed author guidelines. 